\title{
Influência da Irrigação de Soluções Nutricionais no Colo Excluso de Trânsito Intestinal. Estudo Experimental em Ratos
}

\author{
Influence of Irrigation of Nutritional Solutions in the Colon Excluded of Fecal \\ Stream. Experimental Study in Rats
}

\author{
CARLOS GUILHERME GIAZZI NASSRI ${ }^{1}$; ADRIANABASSANINASSRI ${ }^{2}$; EMERSON FAVERO; \\ CARLOS MATEUS ROTTA ${ }^{4}$; CARLOS AUGUSTO REAL MARTINEZ $^{5}$; NELSON FONTANA MARGARIDO ${ }^{6}$
}

\begin{abstract}
${ }^{1}$ Mestre em Gastroenterologia Cirúrgica pelo Hospital do Servidor Público Estadual de São Paulo. Professor Assistente da Disciplina de Técnica Cirúrgica da Faculdade de Medicina da Universidade de Mogi das Cruzes (UMC), São Paulo; ${ }^{2}$ Médica Especialista em Coloproctologia, Mogi das Cruzes, São Paulo; ${ }^{3}$ Professor Assistente de Técnica Cirúrgica da Universidade de Mogi das Cruzes (UMC), São Paulo; ${ }^{4}$ Professor Responsável pela Disciplina de Coloproctologia da Universidade de Mogi das Cruzes (UMC), São Paulo; 5 Professor Adjunto do Programa de Pósgraduação em Ciências da Saúde da Universidade São Francisco (USF). Chefe do Serviço de Cirurgia Geral do Hospital Universitário São Francisco, Bragança Paulista, São Paulo; ${ }^{6}$ Professor Titular de Técnica Cirúrgica da Faculdade de Medicina da Universidade de Mogi das Cruzes (UMC), São Paulo; Professor Livre-Docente do Departamento de Cirurgia da Universidade de São Paulo (USP) - São Paulo - Brasil.
\end{abstract}

\begin{abstract}
NASSRI CGG; NASSRI AB; FAVERO E; ROTTA CM; MARTINEZ CAR; MARGARIDO NF. Influência da Irrigação de Soluções Nutricionais no Colo Excluso de Trânsito Intestinal. Estudo Experimental em Ratos. Rev bras Coloproct, 2008;28(3): 306-314.

RESUMO: A colite por exclusão é descrita como processo inflamatório que ocorre nos segmentos colorretais desprovidos do trânsito fecal. A deficiência dos ácidos graxos de cadeia curta vem sendo considerada como principal fator causal. Objetivo: $O$ objetivo do presente estudo foi avaliar, em modelo experimental de colite de exclusão, a importância da irrigação do segmento desprovido de trânsito com soluções nutricionais na prevenção e tratamento do processo inflamatório. Método: Foram utilizados trinta ratos Wistar, machos, com peso inicial variando entre 350 e 500 gramas, submetidos à derivação do trânsito intestinal através da realização de colostomia proximal e fístula mucosa distal. Os animais foram divididos em três grupos de 10 animais segundo a irrigação do segmento excluso de trânsito ter sido realizada, empregando-se: Grupo SF: solução fisiológica a 0,9\%; Grupo GH: solução de glicose a 50\%; e Grupo AG: solução de ácidos graxos de cadeia curta. Em todos os animais, a irrigação do colo excluso foi realizada em intervalos de quatro dias sendo sacrificados sempre no $21^{\circ}$ pós-operatório. Os fragmentos removidos dos segmentos intestinais foram corados pelas técnicas da hematoxilina-eosina e tricrômio de Masson. As variáveis histológicas estudadas foram: espessura da túnica mucosa, congestão vascular; infiltrado inflamatório e a deposição de colágeno. Os resultados encontrados foram submetidos a estudo estatístico considerando nível de significância de $5 \%$ (p< 0,05). Resultados: Verificou-se que no grupo onde se irrigou o cólon excluso com solução de ácidos graxos de cadeia curta houve menor congestão vascular, menor infiltrado inflamatório e menor deposição de colágeno quando comparado aos demais grupos experimentais. Conclusão: Os resultados do presente trabalho mostram que a irrigação de segmentos desprovidos de trânsito fecal com ácidos graxos de cadeia curta, encontra-se relacionada à melhora no processo inflamatório decorrente visto na colite de exclusão.
\end{abstract}

Descritores: Colite; Colostomia; Ácidos graxos de cadeia curta; glicose; metabolismo.

Trabalho realizado na Disciplina de Técnica Cirúrgica da Faculdade de Medicina da Universidade de Mogi das Cruzes e apresentado ao Programa de Pós-Graduação em Gastroenterologia Cirúrgica do Hospital do Servidor Público Estadual de São Paulo, "Francisco Morato de Oliveira” (HSPE-FMO) para obtenção do Título de Mestre em Gastroenterologia Cirúrgica - São Paulo - Brasil.

Conflito de interesses: Nenhum

Fonte de financiamento: Fundação de Amparo ao Ensino e a Pesquisa (FAEP).

Recebido em 30/05/2008

Aceito para publicação em 19/06/2008 


\section{INTRODUÇÃO}

O cirurgião freqüentemente na prática diária é obrigado a realizar cirurgias que derivam o trânsito digestivo, em decorrência das diversas doenças que acometem o intestino grosso. $\mathrm{O}$ aumento da violência urbana, bem como a incidência cada vez maior de neoplasias do cólon, doença diverticular e doenças inflamatórias intestinais vêm fazendo com que ocorra aumento proporcional na necessidade de realizaremse estomas derivativos. A exclusão intestinal à Hartmann, às colostomias em alça ou em dupla boca são exemplos dos procedimentos habitualmente utilizados em situações de urgência, que determinam à exclusão de trânsito no segmento intestinal situado a jusante do estoma derivativo.

Colite de exclusão (CE), colite por desfuncionalização ou colite por derivação é definida como o processo inflamatório que acomete segmentos colorretais desprovidos de trânsito intestinal. ${ }^{(1)} \mathrm{A}$ enfermidade foi descrita pela primeira vez em $1981 \mathrm{e}$, a partir de então, vem sendo reconhecida com maior frequiência. ${ }^{(1)}$ A maioria dos enfermos apresenta evolução assintomática, contudo a doença pode ser identificada endoscopicamente, em graus variados, na maior parte dos pacientes submetidos à derivação intestinal. Nos doentes sintomáticos, a CE caracterizase pela presença de diarréia mucóide, dores abdominais, tenesmo e eventual perda de sangue pelo ânus. ${ }^{(2)}$ O desconhecimento dessa entidade clínica, bem como dos aspectos macroscópicos encontrados na mucosa do segmento excluso de trânsito, pode fazer com que a CE seja confundida com outras moléstias inflamatórias do intestino, possibilitando o emprego de terapêuticas ineficazes ou a postergação do fechamento da colostomia. $^{(3)}$

Diversas teorias foram propostas para explicar a etiopatogenia da CE e, dentre elas, destaca-se a que relaciona o surgimento da doença com a diminuição dos ácidos graxos de cadeia curta (AGCC) na luz intestinal. Os AGCC representam o principal substrato energético para o metabolismo dos colonócitos. No cólon desprovido de trânsito, a ausência de fibras oriundas da dieta, impede a formação dos AGCC e sua conseqüente absorção e utilização metabólica energética pelas células epiteliais da parede cólica. A deficiência dos AGCC na luz intestinal altera o metabolismo energético oxidativo do colonócito, formando espécies reativas de oxigênio, representadas principalmente pelo radical hidroxila $\left(\mathrm{OH}^{-}\right)$que, agredindo a membrana basal e as junções intercelulares, alteram a função de barreira epitelial contra a translocação de antígenos intraluminares, determinando o processo inflamatório.

Ainda existem controvérsias com relação a melhor opção terapêutica para os doentes que desenvolvem a CE. No entanto, existem evidências que o restabelecimento do trânsito intestinal possibilita a regressão do quadro inflamatório. ${ }^{(4)}$ Diferentes opções de tratamento clínico têm sido experimentadas com intuito de melhorar o processo inflamatório intestinal, até que os pacientes adquiram condições locais e gerais, para a realização da reconstituição do trânsito intestinal. Assim, esquemas terapêuticos empregando diferentes substâncias têm sido propostos, a maioria baseando-se na instilação de várias substâncias no colo excluído. Os ácidos graxos de cadeia curta ${ }^{(3,5)}$, soluções salinas ${ }^{(5)}$; derivados aminosalicílicos e corticóides ${ }^{(6)}$; e glicose hipertônica ${ }^{(1)}$ representam algumas das substâncias anteriormente empregadas. Com o objetivo de comparar a eficácia destas substâncias no tratamento da $\mathrm{CE}$, vários centros, ensaiaram modelos experimentais de colite mostrando, contudo, resultados conflitantes. ${ }^{(7,8,9,10)}$

O objetivo do presente estudo é comparar em um modelo de experimental de CE, a eficácia da infusão intra-retal de diferentes soluções nutricionais para o tratamento das alterações histopatológicas da parede cólica em segmentos desprovidos de trânsito intestinal.

\section{MÉTODO}

Utilizaram-se 30 ratos da raça Rattus Norvegicus Berkenhout da variedade Wistar, machos, com peso inicial variando entre 350 e 500 gramas, correspondendo a 14 semanas de vida, mantidos em gaiolas individuais em sistema alternado de claro/escuro, em temperatura ambiente de $22^{\circ} \mathrm{C}$, alimentados com ração específica e balanceada (Nuvital Nutrientes ${ }^{\circledR}$, Paraná, Brasil), ad libitum. Os ratos foram divididos em três grupos de 10 animais cada, sendo que o processo de inclusão para cada grupo foi realizado de forma aleatória. Os grupos experimentais foram denominados de acordo a substância que seria utilizada da irrigação cólica, a saber: Grupo SF: Irrigação com soro fisiológico; Grupo GH: Irrigação com glicose hipertônica, e Grupo AG: Irrigação com ácidos graxos de cadeia curta. 
Influência da Irrigação de Soluçães Nutricionais no Colo Excluso de Trânsito Intestinal. Estudo Experimental em Ratos Carlos Guilherme Giazzi Nassril e Cols.
Após aclimatação ao ambiente de laboratório durante 72 horas, os animais permaneceram em jejum prévio de 12 horas, recebendo apenas água ad libitum. Os animais foram anestesiados com associação de cloridrato de zolazepan e cloridrato de tiletamina (Zoletil $50^{\circledR}$ - Virbac) numa proporção de 1:1, aplicada por via intramuscular na pata posterior direita do animal, na dose de $50 \mathrm{mg} / \mathrm{Kg}$ peso corpóreo, o que corresponde ao volume de $0,1 \mathrm{ml}$ da solução para cada $100 \mathrm{~g}$ /peso do animal. O preparo da parede abdominal foi realizado por meio de tricotomia e aplicação de polivinilpirrolidona-iodo. Procedeu-se a laparotomia através de incisão mediana próxima ao hipogástrio numa extensão máxima de três centímetros em sentido longitudinal. Após inventário da cavidade, identificava-se o colo, que foi exteriorizado em sua porção média do arco cólico, e com auxílio de paquímetro metálico, aferia-se o diâmetro do colo. Esse segmento do colo foi então seccionado e acondicionado em frasco com solução de formol a $10 \%$, constituindo-se como parâmetro de colo normal (controle). Através da boca cólica distal, foi realizado método de limpeza mecânica anterógrada intra-operatória ${ }^{(10)}$, com a intenção de deixar o segmento distal sem resíduos fecais que poderiam interferir sobre o metabolismo do colonócito. Após a completa limpeza do colo distal, foram confeccionadas contra-aberturas transversais com cinco milímetros de diâmetro, interessando todos os planos da parede abdominal em ambos os flancos. No flanco esquerdo, exteriorizou-se a boca do colo excluído (distal), realizando-se colostomia terminal com maturação precoce. Pela contra-abertura do flanco direito, exteriorizouse o segmento cólico com trânsito intestinal (proximal), confeccionando-se a colostomia com a mesma técnica. Os controles pós-operatórios foram realizados a cada quatro dias (desde o procedimento inicial até o $21^{\circ}$ pós-operatório), com interesse principal às seguintes condições: peso corpóreo; colostomias e ferida operatória.

De acordo com seu grupo experimental realizou-se irrigação através da colostomia distal, com as seguintes soluções: Grupo SF: Solução de cloreto de sódio a 0,9\%; Grupo GH: Solução de glicose hipertônica a 50\%; Grupo AG: Solução de ácidos graxos de cadeia curta (butirato, acetato e propionato, na proporção de 3:2:1 como descrito por Harig et al., em 1989. ${ }^{(5)}$

As irrigações foram realizadas com os animais anestesiados, no quarto, oitavo, $12^{\circ}, 16^{\circ}$ e $20^{\circ}$ pós-operatórios. Através da introdução de sonda de Levine $\mathrm{n}^{\circ}$
10 na colostomia do segmento excluído de trânsito, a irrigação foi feita de maneira suave e contínua até a instilação completa de seis mililitros da solução previamente definida para cada grupo, na temperatura de $25^{\circ} \mathrm{C}$. Após a irrigação, os animais foram recolocados em suas gaiolas individuais, e oferecida ração e água ad libitum.

No $21^{\circ}$ pós-operatório, os animais foram sacrificados por meio da inalação de dose fatal de éter etílico. Verificaram-se, inicialmente, as condições das estomias proximal e distal, bem como da ferida operatória. A inspeção da cavidade foi empreendida com especial interesse para achados cirúrgicos anormais representados por aderências, abscessos e coleções líquidas intra-cavitárias. Foram desfeitas as aderências encontradas, e com auxílio de paquímetro, mediu-se o diâmetro do colo a um centímetro da face interna da parede abdominal, no tocante ao colo correspondente as colostomias no trânsito (proximal) e exclusa dele (distal). Concluída esta etapa, terminou-se a dissecação de todo colo em sentido proximal e distal, sendo as colostomias retiradas em conjunto com a parede abdominal, em peças cirúrgicas únicas. Os segmentos extirpados foram acondicionados em frascos separados, devidamente identificados e fixados em formol a $10 \%$ para posterior análise histológica.

As peças correspondentes ao colo considerado normal (controle), ou seja, retiradas durante procedimento cirúrgico inicial, e os segmentos proximal e distal, correspondentes ao $21^{\circ}$ pós-operatório, foram emblocadas em parafina e coradas pelas técnicas da hematoxilina-eosina e tricrômico de Masson ${ }^{(2)}$. As lâminas foram estudadas por meio de microscopia óptica convencional, no tocante às seguintes variáveis: altura da túnica mucosa; congestão vascular; infiltrado linfoplasmocitário; deposição de colágeno. Todas as lâminas foram analisadas por um histologista e dois cirurgiões. Para cada variável as comparações foram quantificadas em cruzes, a saber: 0 - ausente; + presença discreta; ++ presença significativa; +++ presença moderada e ++++ presença intensa.

Quanto à altura da túnica mucosa, o padrão sempre foi à condição normal (controle), que recebeu a graduação de 10 pontos. Do mesmo modo, as variações foram estimadas em cruzes, para maior ou menor altura. Para cada cruz atribui-se o valor de dois pontos, somados ou subtraídos do valor estabelecido inicial (controle), conforme o achado histológico. 
Rev bras Coloproct Julho/Setembro, 2008
Influência da Irrigação de Soluç̃es Nutricionais no Colo Excluso de Trânsito Intestinal. Estudo Experimental em Ratos Carlos Guilherme Giazzi Nassril e Cols.
Vol. 28 $\mathbf{N}^{\mathbf{0}} 3$
Os dados deste trabalho foram estatisticamente analisados mediante um nível de significância adotado de $5 \%(\mathrm{a} 0,05)$. Desta forma, os valores calculados de probabilidade de erro " $p$ ", quando $p £ 0,05$, foram considerados estatisticamente significantes $(*)$. Os modelos utilizados no cálculo foram predominantemente não paramétricos, tendo-se em vista a mensuração de caráter subjetivo de algumas variáveis e também o número de casos de cada grupo. Utilizaram-se a média aritmética para todas as variáveis, acrescido de desvio padrão para os dados do peso corpóreo e do diâmetro intestinal, e os testes de Kruskal-Wallis, Mann-Whitney, ANOVA, Friedman e Wilcoxon.

\section{RESULTADOS}

\section{Peso Corpóreo}

Os valores mensurados do peso dos animais são mostrados na Tabela 1. Não houve variações estatisticamente significantes entre o peso dos animais, nos diferentes grupos estudados, porém quando este foi avaliado entre os diferentes tempos de estudo, observou-se variação estatisticamente significante, indicando queda inicial abrupta do peso, do inicial ao dia sete, em seguida queda menos acentuada entre os dias sete e 14, com tendência de estabilização entre os dias 14 e 21.

\section{Diâmetro do colo}

Os valores mensurados do diâmetro dos segmentos do colo são mostrados na tabela 2. Não houve variação estatisticamente significante do diâmetro do colo, quando este foi analisado entre os diferentes grupos. Na análise entre os segmentos do colo (controle, proximal e distal), houve variação significante, indicando que o diâmetro do segmento distal do colo, apresenta-se menor, quando comparado aos segmentos controle e proximal.

\section{Altura da Túnica Mucosa}

Os valores de mensuração da altura da túnica mucosa são mostrados na tabela 3. Na análise entre os diferentes grupos não houve variação estatisticamente significante. $\mathrm{Na}$ análise entre os segmentos do colo, para cada um dos grupos estudados (controle, proximal e distal), os resultados indicaram variação significante, mostrando o segmento proximal maior que o controle, e o distal menor que o controle.

Tabela 1 - Média do peso dos animais dos grupos SF, GH e AG, e do total geral, para os diversos tempos considerados (inicial, 7, 14 e 21 dias).

\section{Média \pm Desvio padrão}

\begin{tabular}{llcccc}
\cline { 3 - 6 } Grupo & $\mathbf{N}$ & Inicial & $\mathbf{7 ~ d i a s}$ & $\mathbf{1 4}$ dias & 21 dias \\
\hline SF & 10 & $437,00 \pm 20,44$ & $370,50 \pm 46,75^{*}$ & $344,50 \pm 39,05^{*}$ & $340,00 \pm 45,77^{*}$ \\
GH & 10 & $413,00 \pm 34,98$ & $348,00 \pm 47,09^{*}$ & $342,50 \pm 52,24^{*}$ & $331,00 \pm 30,62^{*}$ \\
AG & 10 & $423,00 \pm 42,44$ & $379,50 \pm 30,23^{*}$ & $348,00 \pm 39,67^{*}$ & $333,00 \pm 47,21^{*}$ \\
Total & 30 & $424,33 \pm 34,18$ & $366,00 \pm 42,80^{*}$ & $345,00 \pm 42,59^{*}$ & $334,67 \pm 40,60^{*}$ \\
\hline
\end{tabular}

$S F=$ soro fisiológico; $G H=$ glicose hipertônica $A G=$ ácidos graxos; $n=$ número de animais; * = significante.

Tabela 2 - Média aritmética dos diâmetros de cada um dos grupos SF, GH e AG, e do total geral, para as medidas dos colos controle, proximal e distal.

\begin{tabular}{lllcc}
\hline & & \multicolumn{3}{c}{ Média \pm Desvio padrão } \\
\cline { 3 - 5 } Grupos & $\mathbf{n}$ & Controle & Proximal & Distal \\
\hline SF & 10 & $7,90 \pm 1,79$ & $8,30 \pm 1,25$ & $2,40 \pm 0,84^{*}$ \\
GH & 10 & $8,10 \pm 1,20$ & $8,40 \pm 1,17$ & $2,40 \pm 0,52^{*}$ \\
AG & 10 & $8,70 \pm 1,16$ & $7,70 \pm 0,95$ & $2,70 \pm 0,82^{*}$ \\
Total & 30 & $8,23 \pm 1,41$ & $8,13 \pm 1,14$ & $2,50 \pm 0,73^{*}$ \\
\hline
\end{tabular}

SF = soro fisiológico; $G H=$ glicose hipertônica; $A G=$ ácidos graxos; $n=$ número de animais; $*$ significante. 
Rev bras Coloproct Julho/Setembro, 2008
Influência da Irrigação de Soluções Nutricionais no Colo Excluso de Trânsito Intestinal. Estudo Experimental em Ratos Carlos Guilherme Giazzi Nassril e Cols.
Vol. 28

\section{Congestão Vascular}

Os valores de quantificação de congestão vascular são apresentados na tabela 4. Quando analisados os diferentes segmentos do colo (controle, proximal e distal), para cada um dos grupos, verificamos variação significante principalmente para o grupo dos ácidos graxos no segmento do colo distal, que mostrou uma menor congestão vascular.

\section{Infiltrado Inflamatório}

Os valores das quantificações do infiltrado inflamatório são apresentados na tabela 5. Não houve variação estatisticamente significante na análise entre os grupos para cada uma das medidas dos segmentos do colo controle, proximal e distal. Na análise entre os segmentos do colo, para os diferentes grupos, houve variação significante, evidenciando diminuição do infiltrado inflamatório no grupo ácidos graxos no colo distal.

\section{Tecido Colágeno}

As médias das quantificações do tecido colágeno, são mostradas na tabela 6 . Na análise entre os grupos, para os segmentos do colo controle, proximal e distal, houve variação estatisticamente significante para os grupos proximal e distal, e para os pares de grupos SF x AG e GH x AG. Na análise entre os segmentos do colo, para cada um dos grupos, houve variação estatisticamente significante, bem como para cada um dos pares de medidas indicando, portanto uma diminuição do tecido colágeno no segmento distal do grupo que foi irrigado com ácidos graxos.

\section{DISCUSSÃO}

As tentativas prévias de se criar um modelo experimental para estudar as colites apresentaram êxito limitado. ${ }^{(11)}$ Nenhum modelo animal atualmente utilizado é perfeito e, tentativas experimentais de se criar no animal um modelo humano de colite, utilizando a infusão retal de agentes químicos tóxicos, tais como o ácido acético, ácido trinitrobenzeno sulfônico (TNBS) ou o sulfato sódico de dextran (DSS), são limitados na sua capacidade de reproduzir fielmente a doença nos seus aspectos psicológicos, fisiológicos, genéticos, ambientais que antecedem e contribuem para a patogênese da

Tabela 3 - Média aritmética das medidas da altura da túnica mucosa nos grupos SF, GH e AG, e do total geral, para as medidas do colo Controle, Proximal e Distal.

\begin{tabular}{lcccc}
\hline & & \multicolumn{3}{c}{ Média da altura das criptas } \\
\cline { 3 - 5 } Grupos & $\mathbf{n}$ & Controle & Proximal & Distal \\
\hline SF & 10 & 10,00 & $13,90^{*}$ & $6,30^{* *}$ \\
GH & 10 & 10,00 & $13,60^{*}$ & $5,70^{* *}$ \\
AG & 10 & 10,00 & $14,00^{*}$ & $6,00^{* *}$ \\
Total & 30 & 10,00 & $13,83^{*}$ & $6,00^{* *}$ \\
\hline
\end{tabular}

SF = soro fisiológico; $G H=$ glicose hipertônica; $A G=$ ácidos graxos; $n=$ número de animais; $*=$ significante maior que o controle; $* *=$ significante menor que o controle.

Tabela 4 - Valores das médias das quantificações de congestão vascular dos grupos SF, GH e AG, para os segmentos do colo Controle, Proximal e Distal.

\begin{tabular}{lcccc}
\hline & & \multicolumn{3}{c}{ Congestão vascular } \\
\cline { 3 - 5 } Grupos & $\mathbf{n}$ & Controle & Proximal & Distal \\
\hline SF & 10 & 0,00 & 13,90 & 3,80 \\
GH & 10 & 0,50 & 1,60 & 3,20 \\
AG & 10 & 1,60 & 1,80 & $1,80^{*}$ \\
Total & 30 & 0,37 & 1,73 & 2,93 \\
\hline
\end{tabular}

SF = soro fisiológico; $G H=$ glicose hipertônica $; A G=$ ácidos graxos; $n=$ número de animais; $*$ significante. 
Rev bras Coloproct Julho/Setembro, 2008
Influência da Irrigação de Soluç̃es Nutricionais no Colo Excluso de Trânsito Intestinal. Estudo Experimental em Ratos Carlos Guilherme Giazzi Nassril e Cols.
Vol. 28 $\mathbf{N}^{\mathbf{0}} 3$

Tabela 5 - Valores das médias da quantificação do infiltrado inflamatório nos grupos SF, GH e AG, para os segmentos do colo Controle, Proximal e Distal.

\begin{tabular}{lcccc}
\hline & & \multicolumn{3}{c}{ Infiltrado inflamatório } \\
\cline { 3 - 5 } Grupos & $\mathbf{n}$ & Controle & Proximal & Distal \\
\hline SF & 10 & 0,20 & 3,10 & 3,40 \\
GH & 10 & 0,00 & 2,60 & 4,50 \\
AG & 10 & 0,50 & 2,40 & $3,30^{*}$ \\
Total & 30 & 0,23 & 2,70 & 3,73 \\
\hline
\end{tabular}

$S F=$ soro fisiológico; $G H=$ glicose hipertônica; $A G=$ ácidos graxos; $n=$ número de animais; $*=$ significante .

Tabela 6 - Valores das médias das quantificações de tecido colágeno dos grupos SF, GH e AG, para os segmentos do colo Controle, Proximal e Distal.

\begin{tabular}{lcccc}
\hline & & \multicolumn{3}{c}{ Colágeno tecidual } \\
\cline { 3 - 5 } Grupos & $\mathbf{n}$ & Controle & Proximal & Distal \\
\hline SF & 10 & 1,40 & 2,40 & 4,30 \\
GH & 10 & 0,30 & 2,60 & 4,60 \\
AG & 10 & 1,10 & 1,20 & $2,60^{*}$ \\
Total & 30 & 0,93 & 2,07 & 3,83 \\
\hline
\end{tabular}

$S F=$ soro fisiológico; $G H=$ glicose hipertônica; $A G=$ ácidos graxos; $n=$ número de animais; $*$ = significante.

doença. ${ }^{(12)}$ Assim sendo, estes modelos experimentais representam apenas em parte o que ocorre nas colites. De modo diferente, a exclusão do trânsito intestinal é modelo experimental facilmente reprodutível em animais e apresenta paralelismo com o que acontece com o ser humano. Animais submetidos à exclusão do trânsito intestinal também desenvolvem alterações inflamatórias na mucosa cólica semelhantes ao que ocorre no homem. ${ }^{(10)} \mathrm{A}$ similaridade entre a CE observada em animais de experimentação e no homem permite maior segurança na interpretação das alterações histológicas, bioquímicas e genéticas encontradas. Assim sendo, modelos experimentais de CE possibilitam maior precisão na avaliação de diversas estratégias terapêuticas que visam melhorar a inflamação da mucosa cólica.

No presente estudo, a opção pelo rato como animal de experimentação deveu-se, inicialmente, à sua facilidade de controle e manipulação, tolerância à dieta padronizada oferecida e resistência natural a infecções. Importante ressaltar a similaridade em relação ao homem, quanto à estrutura da camada submucosa e microflora fecal. ${ }^{(13)}$ A maioria das pesquisas experimentais relativas a CE empregaram o ratos como ani- mal de experimentação. ${ }^{(7,8,9,14,15,16,17)}$ No modelo experimental proposto optou-se pela confecção das colostomias em ambos os flancos, pois esta disposição facilitava as irrigações realizadas ao longo do pós-operatório. A adoção de segmento de colo excluso relativamente longo (quatro centímetros) permitiu irrigação com volume considerável (seis mililitros) sem que houvesse extravasamento do conteúdo ao redor do estoma ou do orifício anal, nos animais estudados. O modelo adotado utilizando colostomia proximal e fístula mucosa distal parece ser superior ao procedimento proposto por Hartmann, pois não existe o risco de promover aumento da pressão intraluminal no segmento intestinal excluso de trânsito quando da irrigação, o que poderia aumentar a pressão na linha de sutura confeccionada para o fechamento do coto distal, bem como também prejudicar a mucosa cólica. Desta maneira, qualquer volume a mais do que o correspondente à capacidade receptiva do colo excluído, extravasaria pelo orifício anal.

O método de limpeza mecânica anterógrada intra-operatória do segmento excluído também merece destaque. É de fundamental importância ressaltar- 
Influência da Irrigação de Soluçães Nutricionais no Colo Excluso de Trânsito Intestinal. Estudo Experimental em Ratos Carlos Guilherme Giazzi Nassril e Cols. se que uma condição uniforme de limpeza, possibilita, desde o início, condição igual para todos os animais nos diferentes grupos experimentais. ${ }^{(10)}$ Some-se a isso o fato de que muitos autores mostraram que o conteúdo fecal pode determinar alterações locais, influenciando nas condições de reação inflamatória, bem como na proliferação bacteriana no interior do segmento excluso. ${ }^{(7,19,20,21,22)}$

Revisão da literatura mostra que o período de derivação do trânsito fecal nas pesquisas experimentais com ratos objetivando o estudo de alterações histológicas encontradas na colite por exclusão, são extremamente variáveis, indo de cinco dias a 17 semanas. ${ }^{(7,8,9,14,15)}$ Na presente pesquisa optou-se pelo tempo de observação de três semanas, período de tempo intermediário em relação aos estudos encontrados na literatura, mas suficiente para promover o aparecimento da doença. Os achados cirúrgicos por ocasião do sacrifício dos animais, bem como os estudos histológicos, demonstraram que este intervalo de tempo adotado foi suficiente para induzir alterações inflamatórias no segmento de intestino grosso excluído do trânsito fecal.

Estudos clínicos inferiram que soluções de ácidos graxos de cadeia curta, poderiam fornecer o substrato energético necessário para auxiliar na cicatrização de processos inflamatórios cólicos. ${ }^{(5)}$ Diferentemente do que acontece no intestino delgado, no colo caso exista menor suprimento de ácidos graxos de cadeia curta, essa deficiência pode ser suprida por corpos cetônicos oriundos da circulação. ${ }^{(23)}$ Quanto a outros aspectos funcionais, sabe-se que os ácidos graxos de cadeia curta aumentam absorção de água e de sódio da luz intestinal. ${ }^{(24,25)}$ Estudos experimentais imputaram à glicose hipertônica, fatores positivos na cicatrização de anastomoses. ${ }^{(19)}$ Outras pesquisas em ratos concluíram que instilação de soluções com concentração elevada de glicose na luz do colo apresenta efeito protetor quanto a prevenção do aparecimento de neoplasias. $^{(26)}$

No presente estudo, a análise do comportamento da altura da túnica mucosa foi uniforme quando se consideraram os grupos experimentais propostos. Quando os diferentes segmentos cólicos (controle, proximal e distal) foram analisados separadamente, constatou-se diferença estatisticamente significante entre eles no que se relaciona a altura da camada mucosa. Quando se comparou os segmentos de colo independentemente do grupo considerado, observou- se que no segmento proximal, ao final de 21 dias, ocorria aumento da altura da túnica mucosa, que variava de 36 a 40\% em comparação com segmentos obtidos no controle. Por outro lado, quando se analisou a evolução desse mesmo parâmetro com relação ao segmento distal, constatou-se diminuição, nesse último segmento, que variava de 37 a $43 \%$. Essa diminuição encontrada encontra-se de acordo com outros estudos anteriormente publicados. ${ }^{(3,8,9,17,25,27,28,29)}$

A totalidade das alterações histológicas, que ocorrem na colite de exclusão ${ }^{(30)}$, não foi identificada no presente estudo, provavelmente em decorrência do curto espaço de tempo de observação considerado. Pode-se imaginar que com maior tempo de exclusão e a manutenção da condição de derivação intestinal, poderiam encontrar-se alterações histopatológicas mais acentuadas, aproximando-se com achados observados por outros autores.

Ao considerar-se a presença de congestão vascular, encontrou-se comportamento histológico diferente no segmento distal, do grupo irrigado com solução de ácidos graxos de cadeia curta quando comparados aos demais grupos. Naqueles animais constataram-se menores índices de congestão vascular, alterações estas com importante significado. Estudos experimentais também verificaram congestão vascular no segmento de colo excluído do trânsito, resultados esses que coincidem com os achados do grupo irrigado com solução fisiológica e glicose hipertônica. ${ }^{(8)}$ Os resultados da presente pesquisa no que dizem respeito à presença de congestão vascular no segmento cólico desprovido de trânsito, evidenciaram menor congestão vascular no grupo irrigado com os ácidos graxos de cadeia curta permitindo concluir que existe um efeito protetor destes nutrientes na prevenção de congestão vascular sobre a submucosa da parede do colo desfuncionalizado.

Quando se avaliou a presença de infiltrado inflamatório, constatou-se que no segmento cólico controle, existia diferença significante em relação aos valores do início do estudo, porém este achado não apresenta significado científico. Por outro lado, quando se procedeu à comparação entre os grupos ao longo do tempo de exclusão, encontrou-se aumento significativo na intensidade do infiltrado inflamatório. Na análise entre segmentos do colo, verificou-se aumento significante quanto à presença de infiltrado inflamatório nos segmentos distais, porém em menor intensidade no grupo irrigado com ácidos graxos. Esses acha- 
Rev bras Coloproct Julho/Setembro, 2008
Influência da Irrigação de Soluç̃es Nutricionais no Colo Excluso de Trânsito Intestinal. Estudo Experimental em Ratos Carlos Guilherme Giazzi Nassril e Cols.
Vol. 28 dos indicam que a exclusão do trânsito digestivo implica no aparecimento de maior quantidade de infiltrado inflamatório, mostrado pelo maior comprometimento deste segmento intestinal. Por outro lado, no grupo irrigado com ácidos graxos de cadeia curta, houve redução do processo inflamatório na porção desfuncionalizada do colo corroborando o papel protetor destas substâncias.

Pode-se argumentar que o comportamento do infiltrado inflamatório entre os grupos experimentais considerados, nos diferentes segmentos de colo, foi similar aos achados da literatura, e desta maneira, afirmar que, além do modelo experimental de colite por exclusão ter sido alcançado, a utilização de ácidos graxos de cadeia curta funcionou como um fator de diminuição do processo inflamatório sobre a mucosa colônica. $\left.{ }^{(7,8} 829,31\right)$

O presente estudo encontrou variação estatisticamente significante nos grupos irrigados com ácidos graxos de cadeia curta no tocante a menor deposição de tecido colágeno, demonstrando que estes ácidos voláteis diminuíam a quantidade de colágeno na parede cólica. Estudos realizados em ratos considerando o metabolismo do colágeno no intestino grosso observaram que no período pós-operatório, existe aumento da síntese de colágeno quando os animais são nutridos com rações com baixo teor de resíduos quando comparados a ratos nutridos com ração normal de laboratório. Concluiu-se que o conteúdo intestinal é um importante fator, e que estimularia a produção de colágeno. ${ }^{(14)}$
Outros autores chamam a atenção para uma nova forma de colite onde ocorre maior quantidade de colágeno no segmento intestinal excluído do trânsito digestivo. ${ }^{(31)}$ Ainda no campo experimental, estudos em ratos avaliando a influência de infusão de ácidos graxos sobre o colo excluído do trânsito, demonstraram que essa estratégia possui grande valor ao promover o aumento da síntese de colágeno ${ }^{(20)}$.

\section{CONCLUSÃO}

A irrigação do colo excluído com solução de ácidos graxos de cadeia curta ao fim de 21 dias, promoveu diminuição do processo inflamatório em segmentos desprovidos de trânsito intestinal. Os resultados obtidos em relação à evolução da congestão vascular e infiltrado inflamatório nos diferentes grupos de estudo, sugerem que os ácidos graxos de cadeia curta possuem efeitos benéficos sobre o colo desfuncionalizado. Do mesmo modo, ao analisarem-se as mensurações de tecido colágeno, verificou-se diminuição nos segmentos distais do grupo irrigado com ácidos graxos de cadeia curta, o que, por inferência, permite concluir a possibilidade da relação entre reação inflamatória na parede cólica e deposição de colágeno na submucosa. Estudos complementares devem ser realizados para elucidação desses aspectos histológicos, que poderiam estar relacionados à fisiopatologia da colite por exclusão.

ABSTRACT: Diversion colitis is described as an inflammatory process that occurs in the colorectal segments excluded of the fecal stream. The deficiency of the short-chain fatty acids inside of intestinal lumen was considered the main etiologic factor. Aim: The aim of the present study was valued, in experimental model of diversion colitis, the importance of the irrigation of the segment without fecal stream with nutritional solutions in prevention and treatment of the colic mucosa inflammation. Method: There were used thirty Wistar males rats, with initial weight varying between 350 and 500 grammas, submitted to the derivation of the fecal stream through proximal colostomy and distal mucous fistula. The animals were divided in three groups with 10 animals according to the irrigation of the excluded colic segment had been carried out with: SF Group: 0.9 \% physiologic solution; GH Group: hypertonic glucose solution of $50 \%$ and AG Group: solution of short-chain fatty acids. In all the animals, the irrigation of the excluded colon was carried each four days and the animals were sacrificed ever in $21^{\text {st }}$ post-operative day. The removed fragments of the intestinal segments were colored by the techniques of hematoxylin-eosin and Masson trichromium. The histological variables studied were: thickness of the mucous layer, vascular congestion; inflammatory infiltrate and the level of tissue collagen. The considered results were subjected to statistical study considering signification level of $5 \%$ (p <0.05). Results: The obtained results showed that in the group where the excluded colon was irrigated with solution of short-chain fatty acids there was less vascular congestion, less inflammatory infiltrated and less collagen deposition when compared to another experimental groups. Conclusion: The results of the present study indicate that in the group receiving the short-chain fatty acid solution there was a decrease in the inflammatory infiltrate and the vascular congestion, as well as a reduction in the deposition of collagen tissue. The irrigation of segments without fecal stream with short-chain fatty acids it improves the inflammatory process found in the diversion colitis.

Key words: Colitis; colostomy; short-fain fatty acids; glucoses; metabolisms. 
Rev bras Coloproct Julho/Setembro, 2008
Influência da Irrigação de Soluções Nutricionais no Colo Excluso de Trânsito Intestinal. Estudo Experimental em Ratos Carlos Guilherme Giazzi Nassril e Cols.
Vol. 28 $\mathbf{N}^{\circ} 3$

\section{REFERÊNCIAS}

1. Glotzer DJ, Glick ME, Goldman H. Proctitis following diversion of fecal stream. Gastroenterology 1981;80:438-41.

2. Ferguson CM, Siegel RJ. A prospective evolution of diversion colitis. Am Surg 1991;57:46-9.

3. Mortensen FV, Langkilde NC, Joergensen JC, Hessov I. Shortchain fatty acids stimulate mucosal cell proliferation in the closed human rectum after Hartmann $ф$ s procedure. Int $\mathbf{J}$ Colorectal Dis 1999; 14:150-4.

4. Orsay CP, Kim DO, Pearl RK, Abcarian H. Diversion colitis in patients scheduled for colostomy closure. Dis Colon Rectum 1993; 36:366-7.

5. Harig JM, Soergel KH, Komorowski RA, Wood CM. Treatment of diversion colitis with short-chain-fatty acid irrigation. N Engl J Med 1989; 320:23-8.

6. Haas PA, Fox Jr TA, Szilagy EJ. Endoscopic examination of the colon and rectum distal to a colostomy. Am J Gastroenterol 1990; 85:850-4.

7. Biondo-Simões MLP, Greca FH, Ioshi S, Abicalaffe MD, Colnaghi MC, Silva EM, et al. Colite do cólon excluso - modelo experimental em ratos. Acta Cir Bras 2000;15(supl. 3):7-11.

8. Keli E, Bouchoucha M, Devroede G, Carnot F, Ohrant T, Cugnenc PH. Diversion-related experimental colitis rats. Dis Colon Rectum 1997; 40:222-8.

9. Kissmeyer-Nielsen P,MortensenFV,Lauberg S, Hessov I. Transmural trophic effects of short chain fatty acid infusions on atrophic, definctioned rat colon. Dis Colon Rectum 1995; 38:946-51.

10. Margarido NF, Nassri CGG, Nassri AB, Rotta CM, Soares LA. Método de limpeza mecânica anterógrada intra-operatória de colo excluído. Estudo experimental em ratos. Rev Col Bras Cir 2003; 30b:42.

11. Hoffmann JC, Pawlowski NN, Kuhl AA, Hohne W, Zeitz M. Animal models of inflammatory bowel disease: an overview. Pathobiology 2003; 20:121-30.

12. Farrell JF, Peppercorn M. Ulcerative colitis. Lancet 2002; 359:331-40.

13. Hermann JB, Woodward SC, Pulasky EJ. Healing of colonic anastomosis in the rat. Surg Gynecol Obstet 1964; 119:269-75.

14. Blomquist $\mathrm{P}$, Ahonen J, Jiborn H, Zederfeldt B. The effect of relative bowel rest on healing of colonic anastomosis. Collagen synthesis and content in the colonic wall after left colon resection and anastomosis in the rat. Acta Chir Scand 1984;150:677-81.

15. Roediger WEW. The effect of bacterial metabolites on nutrition and fuction of the colonic mucosa. Symbiosis between man and bacteria. In: Kasper H, Goebell H, editors. Colon and nutrition. Lancaster: MTP Press; 1982b. p.11- 24.

16. Rolandelli RH, Koruda MJ, Settle G, Rombeau JL. Effects of intraluminal infusion of short-chain fatty acidas on the healing of colonic anastomosis in the rat. Surgery 1986; 100:198-204.

17. Sakata T, von Engelhardt W. Stimulatory effect of short-chain fatty acids on the epithelial cell proliferation in rat large intestine. Comp Biochem Physiol A 1983; 74:459-62.
18. Nassri CGG, Margarido NF, Nassri AB, Rotta CM, Soares LA. Modelo experimental de colite por exclusão. XXIV Fórum de Pesquisa do Colégio Brasileiro de Cirurgiões. Rio de Janeiro, Brasil, out. 2003.

19. Aguilar-Nascimento JE, Oliveira-Neto JP, Mathie RT, Robin $\mathrm{CN}$, Willianson MA. Effect of intraoperative nutrition solutions on perianastomotic colonic mucosa in experimental large bowel obstruction. Dig Dis Sci 1997; 42:2581-4.

20. Greca FH, Biondo-Simões MLP, Martins VDM, Araújo FH, Milano JB. Os ácidos graxos de cadeia curta na cicatrização de anastomoses colônicas: estudo experimental em ratos. Rev Col Bras Cir 2003 30:268-74.

21. Martínez-Mas E, Vásques-Prado A, Larrocha-Grau M, Artigues-Sanchez E, Lloris-Carsí JM, Trullenque-Peris R. The impact of low-residue enteral feeding on the healing of colonic anastomoses. Hepatogastroenterology 1993; 40:481-4.

22. Rotta CM. Influência do preparo do colo, na evolução da anastomose intestinal nos dois primeiros dias de pós-operatório. Estudo experimental. São Paulo, 1998. 100p. Tese [Doutorado] IAMSPE - Hospital do Servidor Público Estadual "Hospital Francisco Morato de Oliveira".

23. Rowe WA, Bayless TM. Colonic short-chain fatty acids: fuel from the lumen? Gastroenterology 1992; 103:336-8.

24. Hove $\mathrm{H}$, Mortensen PB. The influence of intestinal inflammation (IBD) and small and large bowel length on fecal short-chain fatty acids and lactate. Dig Dis Sci 1995; 40:1372-80.

25. Scheppach W, Bartran P, Richter A, Richter F, Liepold H, Dusel $\mathrm{G}$, et al. Effect of short- chain fatty acids on the human colonic mucosa in vitro. JPEN J Parenter Enteral Nutr 1992; 16:43-8.

26. Hulin SJ, Singh S, Chapman MA, Langman MJ, Eggo MC. Sulphide-induced energy deficiency in colonic cells is prevented by glucose but not by butyrate. Aliment. Pharmacol Ther 2002; 16:325-31.

27. Ruppin H, Bar-Meir S, Soergel KH, Wood CM, Schmitt JR. Absorptionof short chain fatty acids by the colon. Gastroenteroloy 1980; 78:1500-7.

28. Appleton GV, Williamson RC. Hypoplasia of desfunctioned rectum. Br J Surg 1989; 76:787-9.

29. Geraghty JM, Talbot IC. Diversion colitis: histological features in the colon and rectum after defunctioning colostomy. Gut 1991; 32:1020-3.

30. Komorowski RA. Histologic spectrum of diversion colitis. Am J Surg Pathol 1990; 14:548-54.

31. Giardiello FM, Lazenby AJ, Bayless TM. The new colitides. Collagenous, lymphocytic, and diversion colitis. Gastroenterol Clin North Am 1995; 24:717-29.

\section{Endereço para correspondência:}

\section{CARLOS GUILHERME GIAZZI NASSRI}

Rua Coronel Cardoso Siqueira, 3232, Quadra 28, lote 7.

Mogi das Cruzes - São Paulo.

Caixa Postal 274.

E-mail: guilhermito@ hotmail.com 